\title{
Female Hermaphroditism and Term Pregnancy: About a Case at the National Hospital of Pikine and Review of Literature
}

\author{
Taliana Stephie Gondjout ${ }^{*}$, Omar Gassama, Soukaina El Alaoui, Helene Chami, Abdoul Aziz Diouf, \\ Alassane Diouf
}

Gynecological and Obstetric Clinic, Aristide Le Dantec University Hospital, Dakar, Senegal

Email address:

gondjout@gmail.com (T. S. Gondjout)

${ }^{*}$ Corresponding author

\section{To cite this article:}

Taliana Stephie Gondjout, Omar Gassama, Soukaina El Alaoui, Helene Chami, Abdoul Aziz Diouf, Alassane Diouf. Female Hermaphroditism and Term Pregnancy: About a Case at the National Hospital of Pikine and Review of Literature. Journal of Gynecology and Obstetrics. Vol. 7, No. 5, 2019, pp. 142-144. doi: 10.11648/j.jgo.20190705.14

Received: August 8, 2019; Accepted: September 16, 2019; Published: October 9, 2019

\begin{abstract}
This case report, it's about a patient I met during prenatal consultation, she was in the $2^{\text {nd }}$ semester of her pregnancy, exactly at 25 weeks. During the physical examination, we found, she had a hypoplasia of minor labia, an incomplete vaginal diaphragm with a vaginal cup, and a hypertrophy of clitoris. We decide to make some biological and instrumental examinations. After getting the result, we concluded she has a pseudo hermaphroditism associated with malformation of $1 / 3$ of vagina. Reason why the way of the delivery choose was a C-section. Female pseudo hermaphroditism is the most frequent (FPH) sexual ambiguity. It is characterized by the extension of abnormality of the sexual differentiation during the fetal life in the female fetus by a maternal or fetal hyper-genesis. The authors propose through a clinical case with a patient 46XX DSD pregnant. The main cause of this pathology is congenital adrenal hyperplasia, which we lead to deficits of 21-hydoxylase, 11-beta-hydroxylase, 3-beta-hydroxysteroid dehydrogenase, but $95 \%$ of the congenital adrenal hyperplasia is the deficiency of 21-hydoxylase. The treatment of congenital adrenal hyperplasia depend of the cause, hormone replacement therapy like (dexamethasone, hydrocortisone), most often the treatment for life is needed. From this we propose to make review of literature focusing on it.
\end{abstract}

Keywords: 46 XX DSD, Karyotype, Pregnancy, Congenital Adrenal Hyperplasia

\section{Introduction}

Female pseudo hermaphroditism (FPH) is the most common affection of sexual ambiguities [6]. It characterized by the expression of an abnormality of the sexual differentiation during the fetal life in the female fetus by a maternal or fetal hyper androgynous. Congenital adrenal hyperplasia is most often the cause. The karyotype is of the female type $(46, \mathrm{XX})$ and therefore the choice of sex does not arise in these patients [2].

We report a clinical case diagnosed at the Pikine National Hospital in the suburbs of Dakar, Senegal, and then we will make an adjustment for the diagnosis and diagnosis and management of female pseudo hermaphroditism and pregnancy.

\section{Observation}

\subsection{Clinic}

It was 20-year-old Mrs. Maguette N, single, who came to the Gynecology Clinic of the Pikine Hospital Center on September 15, 2017 for prenatal monitoring of her pregnancy estimated at 25 weeks of amenorrhea. The patient had no particular pathological history with regular menstruation since the age of 15 years.

The general examination found a height of 63 inches for a weight of $132 \mathrm{lbs}$. with a body mass index of 23.4; a blood pressure of $120 / 78 \mathrm{mmHg}$. The secondary sexual characteristics (breasts, axillary and pubic hair) corresponded 
to the female morphology and the voice was feminine.

In addition she had a good general condition, well colored conjunctival mucous membranes, with an absence of edema of the lower limbs. The obstetrical examination showed symmetrical breasts, uterine height at 7, 87 inches, head down, left back, absence of uterine contractions, regular fetal heart sounds, and 144 beats per minute. The perineal-vulvar inspection showed hypoplasia of the labia minors, a particular hyperplasia of the clitoris which measured 2 inches as reported in Figure 1. Vaginal touch reported an incomplete 1,57 inches vaginal diaphragm with a vaginal cup.

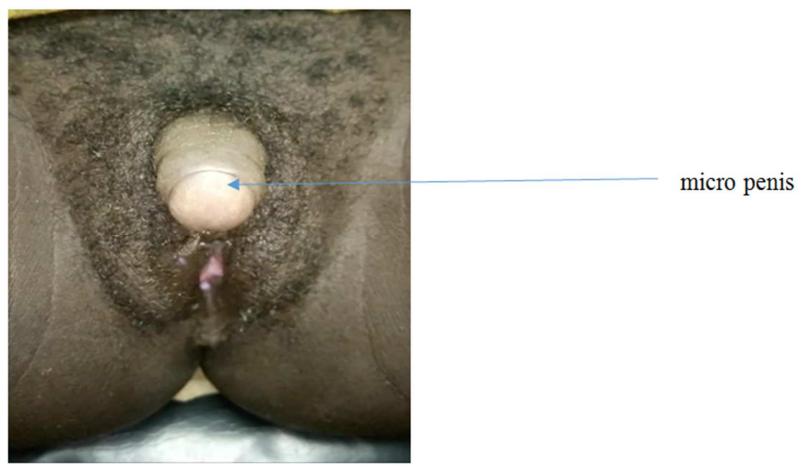

Figure 1. Vulvar-perineal examination.

\subsection{Para Clinical Examinations}

The karyotype was of the female type 46, xx. An obstetrical ultrasound had found one active intrauterine fetus pregnancy of 25 weeks of amenorrhea. The hormone balance showed a plasma level of 17-hydroxy-progesterone at $0.60 \mathrm{ng} / \mathrm{ml}$. It was a 20-year-old prim parous with a 46 XX DSD karyotype bearing a 38 SA pregnancy according to a late ultrasound associated with a pseudo female hermaphroditism stage 3 according to the Prader classification [3] (Vagina). The urethra, itself attached to the base of a peno-clitoris organ).

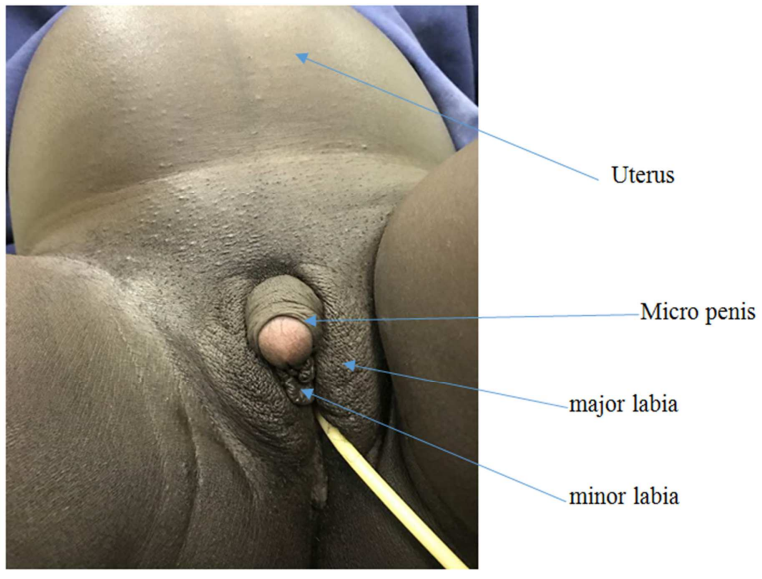

Figure 2. Day of the surgery.

\subsection{Supported}

She had benefited from five prenatal consultations which were without particularities. The patient had benefited on December 11, 2017 (38 weeks of amenorrhea) from a prophylactic caesarean section for vaginal diaphragm. Caesarean section had allowed the extraction by cephalic enucleation of a newborn male weighing $3340 \mathrm{~g}$ with an Apgar score of 8 in the first minute and $9 / 10$ in the fifth minute. The operative sequences were peculiarities.

\section{Discussion}

\subsection{Pathogenesis}

Female pseudo hermaphroditism is a congenital anomaly of rare sexual differentiation, characterized by the presence of normal sex chromosomes and gonads, and masculinization of the external genitalia. The most common cause is congenital adrenal hyperplasia [2].

Congenital adrenal hyperplasia $(\mathrm{CAH})$ is a hereditary endocrine disorder caused by deficiency of steroidogenesis enzymes. These are deficits of 21-hydoxylase, 11-betahydroxylase, and 3-beta-hydroxysteroid dehydrogenase. It is due in $95 \%$ of cases to 21 hydroxylase deficiency (Figure 1) and $90 \%$ of cases Pseudo Hermaphroditism Feminine, it is the second congenital endocrinopathy by its frequency $[1,2]$.

a) Deficiency of 21-hydroxylase will lead to an accumulation of progesterone, 17 alpha-hydroxyl progesterone and a decrease in aldosterone synthesis.

b) The accumulation of 17 alpha-hydroxyl-progesterone will lead to an increase in the production of testosterone which will lead to masculinization of the female genitals. In addition, the deficit in aldosterone can lead to the birth of a salt loss syndrome leading to the death of the child.

\subsection{Diagnostics Aspects}

On the clinical level, there are two form:

a) Classical form

The absence of the enzyme is complete leading to a virilization leading to sexual ambiguity and a loss of salt syndrome with fetal risk in the first weeks of life at birth or in the neonatal period; symptoms usually appear in the first 2 weeks of life and include: hyponatremia, hyperkalemia, and low blood pressure.

The diagnosis of girls is made at birth with the presence of ambiguous genitalia. Fetuses can be diagnosed during the prenatal period by measuring 17-hydroxy-progesterone (17OHP) in the amniotic fluid.

b) The unconventional form

At late onset when production the enzyme is of the order $30 \%$ of normal causing signs of virilization only after puberty. Depending on the degree of hyperandrogenism; PRADER has listed the different cases of intersexuation according to 5 types [2]:

Our case presented the unconventional form with a stage III DE PRADER which is characterized by the fusion of the labia major which is completed and surrounds a single orifice opening on a urogenital sinus.

The diagnosis is based on pelvic ultrasound, which confirms the presence of internal genital organs of the female 
type whose morphology and echo structure are normal. Hysterosalpingography provides essential information on the conformation of the genital tract. An assay of normal 17hydroxy-progesterone represents $2 \%$ of cases of female pseudo-hermaphroditism.

c) Others forms

Deficiency of 11-beta-hydroxylase in its classical form will cause hypertension and a syndrome of virilization.

\subsection{Therapeutics Aspects}

a) The classic form of 21-hydoxylase deficiency is prenatal treatment with dexamethasone administered to female fetuses at risk from 9 weeks of pregnancy. If the diagnosis is made after birth a vaginoplasty is usually performed during the first year. Hormone replacement therapy for life is needed to treat adrenal insufficiency to reduce high levels of androgens and allow normal growth and puberty [15].

b) Our patient did not receive prenatal treatment with dexamethasone or vaginoplasty.

c) The unconventional form of 21-hydoxylase deficiency, as was the case in our patient. The therapeutic action will depend on the hormone level of 17-OHprogesterone and will aim to slow down the secretion of ACTH by moderate dose administration. Hydrocortisone or dexamethasone. One surgery may be considered for external genital repair and will consist of clitoridoplasty, labiaplasty and vaginoplasty. Psychotherapy is an essential component of treatment as long as the patient is around her [2].

d) The treatment of 11-beta-hydroxylase deficiency is based on the administration of hydrocortisone [14].

e) Virilizing adrenal tumors of the pregnant woman are very rare and often malignant; are responsible for an abnormality of sexual differentiation. As well as taking certain drugs (synthetic progestin, anabolic steroids, ACTH analogues, metopirone, anticonvulsants) during the first months of pregnancy is likely to masculinize the genitals of a female fetus [16].

\section{Treatment}

The course of dealing with a term pregnancy associated with a pseudo female hermaphroditism is a prophylactic caesarean section because of incomplete vaginal diaphragm. The patient received a prophylactic caesarean section at 38 weeks of amenorrhea, which resulted in the extraction of a newborn male weighing 7, 4 lbs. and a height of 22 inches, Apgar 8/10 at the first minute and $9 / 10$ in the 5 th minute.

The delivery route depends on the associated malformations and in our patient we performed a prophylactic caesarean section because in addition to clitoral hypertrophy, the patient has an incomplete vaginal diaphragm.

\section{Conclusion}

The pseudo female hermaphroditism is the most frequent affection of sexual ambiguities, when it is associated with a pregnancy as in this clinical case, the interest is even greater.

From a practical point of view, the etiological diagnosis procedure must begin with a clinical examination of anomalies of external genital development, a karyotype and a hormone balance (17-hydroxy-progesterone).

The management is multidisciplinary combining medical, surgical, and psychological treatment, and the patient may decide to undergo surgery later for clitoridoplasty, vaginoplasty, labiaplasty.

\section{References}

[1] N. El amrani, m. Outifa, s. Nabil, i. Chemry, s. El hajoui, mt. Alaoui. A propos d'un cas de pseudo-hermaphrodisme féminin, med du maghreb 2000 n 80.

[2] Mm niang, 1. Niang, w. Kalai, sm gueye, ct cisse le pseudohermaphrodisme féminin, med d'afrique noire juin 2015 , vol 62. N 5 .

[3] C. Pienkowski - a. Cartault anomalie du développement sexuel du nouveau-né- diu maternité Novembre 2008.

[4] Le maillon faible l'abs des syndromes 1990, page 438-448.

[5] D. Ndour, p.m. faye, a.sagna, d. Gueye, a.s. signate $46 \mathrm{xx}$ male or ovotesticular dsd sry negative.

[6] Francois. R. Ambiguïté sexuelle; rev. Fr. Gynécol. Obstet. 1986, 81, 445-450.

[7] Kuttenn f., perby s., lebouc y. Anomalie de la différenciation sexuelle. Méd. Reprod. Mauvais jarvis p. - gynécologie endocrinienne, r. Situk ware, 2e ed, paris, 1988-pp 282-213.

[8] Adriana chedel, elodie fatio, sarah kiehl, audrey perseghini, variations du developpement sexuel, travail de mobilité en partenariat avec la faculté de médecine tuteur: philippe garnerin juin 2013.

[9] Dr saim sid ahmed, dr haffaf anis, «malformations genitales chez les nouveaux-nes», encadré par: dr blidi, année universitaire: 2013-2014.

[10] Deficit en aromatase placentaire et pseudohermaphrodisme feminin, medecine/sciences 1994; jo: 342-3.

[11] Muhammad tahir m bhinder, amin saleh halum and sandy lee, pseudohermaphroditism: a multi-faceted pathosis, nova southeastern university, palm beach gardens, Florida, USA.

[12] Hugh jolly, female pseudohermaphroditism: a description of two unusual cases., proc $r$ soc med. 1959 apr; 52 (4): 300-301.

[13] Perloff wh, conger kb, ley l. Female pseudohermaphroditism: a description of two unusual cases. J clin endocrinol. 1953; 13: 783-790. [pub med].

[14] Guide médecin - pnds «hyperplasie congénitale des surrénales».

[15] Pr juliane leger, hyperplasie congénitale des surrénales par déficit en 21-hydroxylase classique, octobre 2012.

[16] G masson, paris, 1998 annales d'endocrinologie (paris) 1998, 59, 311-31. 